\title{
Experimental and Numerical Evaluation of Concentrically Loaded RC Columns Strengthening by Textile Reinforced Concrete Jacketing
}

\author{
Dang Quang Ngo ${ }^{\text {a }}$, Huy Cuong Nguyen ${ }^{a^{*}}$, Dinh Loc Mai ${ }^{a}$, Van Hiep Vu ${ }^{\text {a }}$ \\ ${ }^{a}$ Faculty of Construction Engineering, University of Transport and Communications (UTC), No. 3 Cau Giay Street, Hanoi, 10000, Viet Nam.
}

Received 14 April 2020; Accepted 02 July 2020

\begin{abstract}
Nowadays, Textile Reinforced Concrete (TRC) has become a very popular strengthening technique for concrete structures. This paper presents an investigation on the applicability of TRC for strengthening reinforced concrete column. Both experimental and numerical studies are conducted to evaluate the confinement effects of various TRC strengthening schemes. The experimental study is performed on a series of six reinforced concrete square columns tested to failure. Two of them were un-strengthened as references, the other four were strengthened by one or two layers of Carbon Textile Reinforced Concrete (CTRC). The results indicated that the application of carbon TRC enhanced the ductility and ultimate strength of the specimens. Failure of all strengthened columns was together with tensile rupture of textile reinforcements at the corners of column. Finite element models of the CTRC strengthened columns based on ATENA software package were developed and verified with the experimental results. The analytical results show that in the specimen corner areas, textile reinforcements are subjected to a 3D complicated stress state and this may be the cause of their premature failure.
\end{abstract}

Keywords: Textile Reinforced Concrete; Strengthen; Column; Confinement; Carbon Textile; ATENA.

\section{Introduction}

Reinforced Concrete (RC) columns as important structural members that transmit gravity and lateral loads to foundation in building structures and brittle failure of RC column may result in the entire collapse of building. Existing RC columns may require strengthening for a variety of reasons, for example: load increases due to higher live loads; change in the facility use; damage to structural parts due to fire damage, corrosion of steel reinforcement, etc. There are numerous methods available to retrofit RC columns, each with relative performance and practical strengths as well as weaknesses. Currently, the most preferable, efficient and practiced methods are RC jacketing and FRP wrapping. $\mathrm{RC}$ jacketing aims at increasing capacity of the structure by increasing its axial load capacity, shear strength, flexural strength and ductility. However, it requires a large jacket thickness, in normal cases higher than 70-100 mm, leading to decrease architectural area while increasing total mass of structure. This method is also not very suitable for structures in corrosive environments. On the other hand, FRP wrapping has advantages over concrete jacketing method such as much less thickness, lower weight and better constructability. However, strengthening performances are only limited to shear strength and deformation capacity. Axial load capacity can be increased by confinement effect, but is limited in extent. Besides, durability matters like fire, ultraviolet radiation, thermal cycles, and humidity should come into consideration when applying these methods.

\footnotetext{
* Corresponding author: nguyenhuycuong@utc.edu.vn
} 
Recently, a new strengthening technique using Textile Reinforced Concrete (TRC) jacket to complement the weak points of existing method has been researched and applied to real structures. TRC combines multi-axial high strength textile reinforcements with fine grained concrete. This combination results in a composite material with many advantages: high tensile strength, high corrosion resistance, and with appropriate materials and configuration, additional corrosion protection for existing concrete reinforcement. TRC strengthened layer also has the advantages of being fully compatible to concrete structures and possessing excellent fire resistance, in contrast to the corrosion and fire protection needs of other techniques where steel is exposed or where epoxy resins are used. The TRC retrofit method for RC columns is able to reduce the minimum jacket thickness up to $10-30 \mathrm{~mm}$, and the retrofitting process using textile reinforcement shows easier fabrication than normal steel reinforcement. Also, due to the high compressive strength of fine grained concrete, it is expected to have superior strengthening performance compared to other column retrofitting methods.

In literature, although extensive research was done on TRC strengthening system within the past decades, only few recent works investigate the axial behavior of TRC-confined RC columns. The American ACI 549.4R-13 is currently the only available guideline for design and construction of strengthening systems. The results of earlier research conducted by Ortlepp et al. [1] and subsequent studies by a number of researchers confirm that TRC jacketing confines concrete, and hence increases the strength and ductility of jacketed columns. The confinement effectiveness of TRC jackets in concrete columns also depends on several parameters which include cross-sectional shape, corner radius (chamfer), and number of textile layers.

Ortlepp et al. [1] tested experimentally the behaviour of strengthened RC columns with all possible cross-sections from square to circle with different transition radiuses. The tested results show a considerable disproportionate increase of the confinement effect with rising transition radius, as well as a growth of the confinement effect with augmenting level of reinforcement in the TRC-strengthening layer. Triantafillou et al. [2] concluded that TRC confining jackets provide substantial gain in compressive strength and deformation capacity after experimentally investigating the use of TRC to confine RC columns. This gain increases as the number of textile layers increases and is dependent on the tensile strength of the fine grained concrete, which determines whether failure of the jacket occurs due to textile rupture or debonding. Triantafillou also reported that the bearing capacity increase of a textile concrete strengthening is more effective at round columns than at their counterparts with a square cross-section. Regarding to the failure of TRC layer, Ortlepp [3] concluded that, if the tensile strength of the fine-grained concrete is exceeded, spalling will happen in the concrete cover and thus to a loss of cross sectional area, as well as partial damage of the bond surface of the textile reinforcement. This may result in a "zipper-like" failure of the anchorage so that the textile reinforcement "decoils" from the column. Bamdad et al. (2016) [4] wrapped TRC for 27 RC columns with different cross-sectional shapes. Experimental results indicated that TRC wrapping can significantly enhance the load-bearing capacity (up to 71 percent) and ductility of RC columns. In non-circular columns, the confinement is concentrated at the corners rather than over the entire perimeter. De Caso y Basalo et al. [5] tested with different reinforcement ratios and used a bond breaker between concrete and jacket to facilitate reversibility. The experimental results indicated that the tested TRC systems produced noticeable increases in both strength and deformability of concrete cylinders. The test conducted by Trapko et al. [6] indicated the effect of the PBO reinforcement of eccentrically compressed columns on their stiffness depending on the level of stress intensity. Piero et al. [7] investigated the effectiveness of the use of PBO textile for wrapping low strength concrete specimens. They highlighted the use of a FGC determines a "delay" in activating the confinement system, and a post-peak stiffness degradation was also observed. Donnini et al. [8] investigated the use of FRP and TRC jackets to reinforce scaled concrete columns and reported that, TRC systems proved to be less effective than FRP in concrete confinement. Concrete cylinders confined with FRP failed due to rupture of fiber, while the failure observed in TRC confined specimens was due to the slippage of the fabric within the matrix.

In literature, few such experiments are available to determine the value of effective ultimate strain of textile in the complex position, such as the corner of rectangular columns. A smaller corner radius can significantly reduce the ultimate strength of the textile due to the stress concentration around the corner area. Piero et al. [9] investigated the effect of the confinement level, the cross-section shape and the corner radius on the stiffness, strength, and ductility of Carbon TRC confined concrete columns, testing several specimens with circular, square and rectangular cross-sections. They concluded that only for the rectangular columns, the corner radius had a non-negligible influence on ultimate strain value, and consequently, on the absorbed energy capacity.

In terms of design limitations, the ACI 549.4R-13 guideline [10] states that the axial strength increase should not exceed $20 \%$ of the existing capacity of the as-built column. Based on the report of Bournas et al. [11], these guidelines also suggested that the strengthening of existing columns should be limited to elements having a cross section with a maximum dimension of $610 \mathrm{~mm}$ for the long side (rectangular) or diameter (circular).

TRC confined concrete structures are of interest and opens up significance for future research. The compressive behavior of strengthened RC columns is influenced by many parameters. The cross-section shape and the corner radius, number of textile layers and the effective ultimate strain value are among the most controversial parameters. Up 
till now, their effects have not been definitely fully defined. The overarching goal of this study was to explore the effectiveness of carbon TRC jacket for use in strengthening square RC columns. This paper describes the experimental program carried out in terms of materials specification, specimen fabrication, and experimental setup. The test results will be summarized in terms of compressive behavior, axial load - axial strain response, axial load - transverse strain response, and energy absorption. Due to the high binder content, fine grained concrete in this test has a lower elastic modulus compared to the ordinary concrete of similar strength grades. This paper will also compare the effect of low elastic modulus of fine grained concrete on strengthened columns to the related work in the literature. In order to validate the experimental results, finite element models of wrapped columns were developed and analyzed. An extensive parametric study of the effective strength of textile roving in corner of strengthened models is conducted to investigate the reduction of tensile strength in textile reinforcement. This research will also increase knowledge of the behavior of confined concrete and help in further developing the theoretical model.

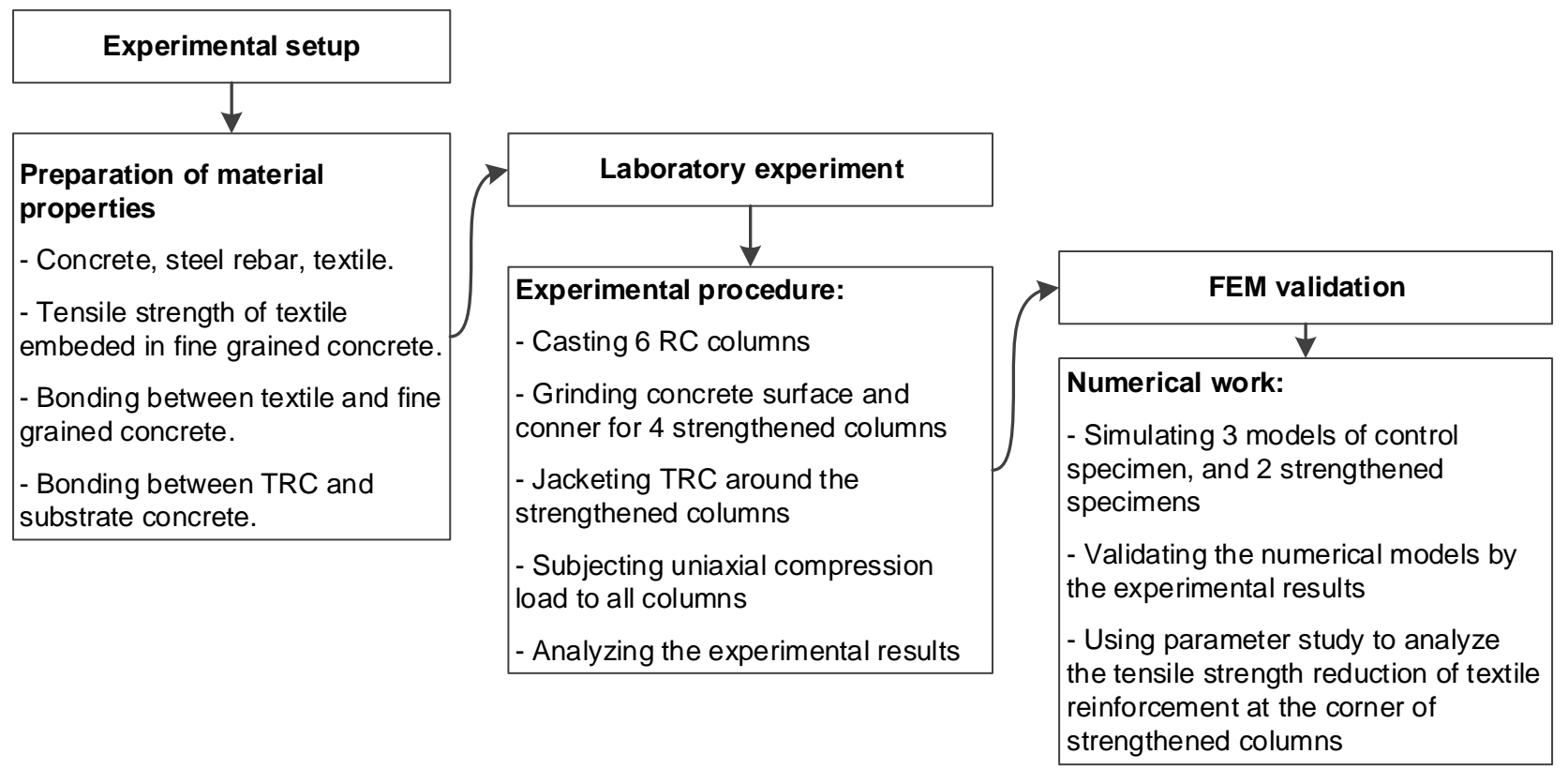

Figure 1. Research methodology flow chart

The brief research methodology flow chart as shown in Figure 1 has been adopted in order to achieve the objective of the study. The following section will present the full description of the two phases of the experimental program. Phase 1 is preparation details of the material properties, including: concrete, steel rebar, tensile strength of textile embedded in fine grained concrete; bonding between textile and fine grained concrete; and bonding between TRC and substrate concrete. The $2^{\text {nd }}$ phase is the laboratory experiment: casting test specimens, surface preparation, strengthening procedure and the test set-up. After finishing the tests, all experimental results will be analyzed. The finite element modeling was continuously conducted to validate with the experimental results. Then, using parameter study, the tensile strength reduction of textile rovings at the corner of strengthened column was analyzed.

\section{Experimental Program}

\subsection{Test Specimens}

For this study, six RC column specimens were designed and manufactured. The columns were $800 \mathrm{~mm}$ long, with cross section dimensions of $200 \times 200 \mathrm{~mm}$. The height of the columns was chosen as $800 \mathrm{~mm}$ due to the maximum height of a sample that can be tested in the hydraulic testing machine. Two columns were left unconfined and used as control specimens to determine their actual limit strength. The unconfined specimens were named $\mathrm{C} 0-1$ and $\mathrm{C} 0-2$. Two columns, namely C1-1 and C1-2, were wrapped with 1 layer of carbon textile. The remaining two columns, C2-1 and C2-2, were upgraded with 2 layers of carbon textile. These columns were eccentrically loaded in compression and tested until the collapse.

All concrete columns were reinforced with four $12 \mathrm{~mm}$ rebars located at section corners and nine $6 \mathrm{~mm}$ diameter steel stirrups. The clear concrete cover was kept as $25 \mathrm{~mm}$ from the bottom to the top and $20 \mathrm{~mm}$ from sides. The longitudinal reinforcement percentage equaled $1.13 \%$. The stirrups for concrete columns were reinforced in confinement in such a way that failure is directed to the middle (namely "weak part"), while the two ends were overreinforced (namely "strong parts"). For this reason, the weak part has stirrups with a distance of $200 \mathrm{~mm}$. In contrary, the "strong part" has each 4 stirrups with a distance of $50 \mathrm{~mm}$. Figure 2 shows the geometry and steel reinforcement configuration of control columns and strengthened columns. All sample columns had the same cross-sectional 
geometry before strengthening. After concreting and curing, the four to be strengthened columns were grinded at the corners with a radius of $30 \mathrm{~mm}$ to avoid the sharp bend of textile reinforcement in strengthening. In order to prevent the "zipper-like" failure of the anchorage, an overlapping layer was applied for each column. After strengthening, sections in confined columns were $220 \times 225 \mathrm{~mm}$ and $230 \times 235 \mathrm{~mm}$ for column C1-1 and C2-1, respectively. The length or TRC jacketing equaled $800 \mathrm{~mm}$ (full length of column).
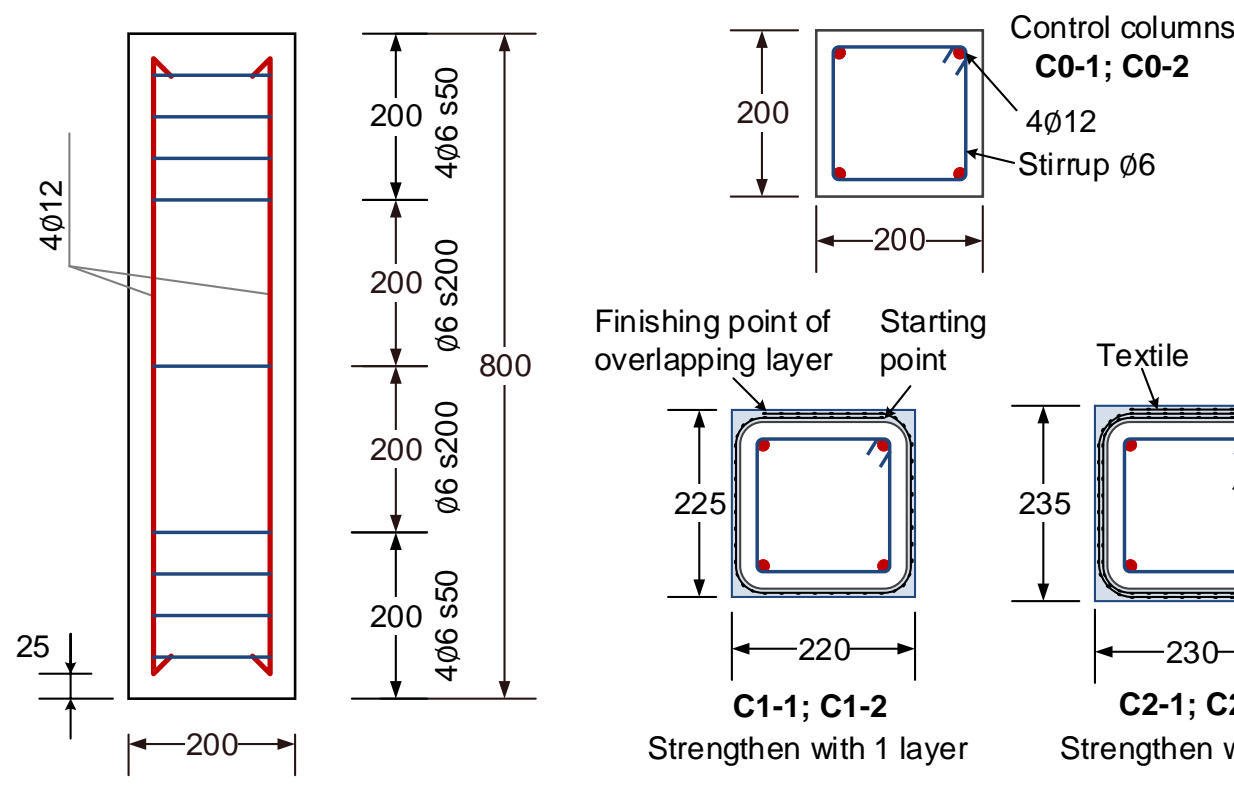

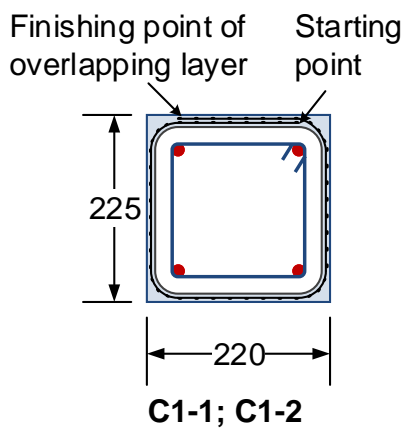

Strengthen with 1 layer

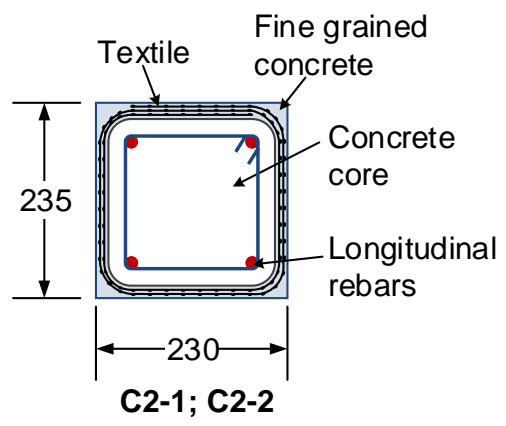

Strengthen with 2 layers

Figure 2. Geometry and steel details of test columns (Unit: $\mathbf{m m}$ )

\subsection{Material Properties}

All column specimens were fabricated using normal strength concrete. The average cylinder compressive strength of the concrete used for the columns was 39.5 MPa. Mechanical characteristics of steel reinforcement were obtained from tensile testing results. Deformed steel bars of diameter $12 \mathrm{~mm}$, with the actual yield strength $f_{y}=425 \mathrm{MPa}$ was use for longitudinal reinforcement. For stirrup, steel bar of $8 \mathrm{~mm}$ in diameter with nominal yield strength $f_{y}=363 \mathrm{MPa}$ was used for all columns. The fine grained concrete (FGC) specifically designed for application with carbon textile was comprised with a maximum grain size of $0.6 \mathrm{~mm}$ and high-fineness cement binder. The high performance plasticizer and fly ash were added to achieve a very good flowing capability of the concrete in order to ensure a proper penetration of the small gaps of the fabrics. The FGC was mechanically characterized by testing six $40 \mathrm{~mm} \times 40 \mathrm{~mm} \times$ $160 \mathrm{~mm}$ prisms. The obtained average flexural strength and average compressive strength at 28 days were equal to 6.5 $\mathrm{MPa}$ and 44.2 MPa, respectively. The average value of elastic modulus of FGC is $17000 \mathrm{MPa}$, much smaller than the one of ordinary concrete with similar strength grades. This can be explained by the low amount of aggregates and the high binder content.

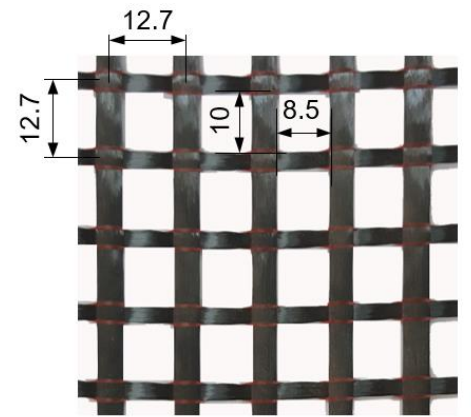

a) Carbon textile

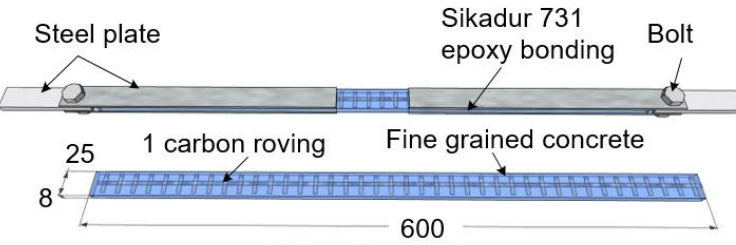

b) Tensile specimen

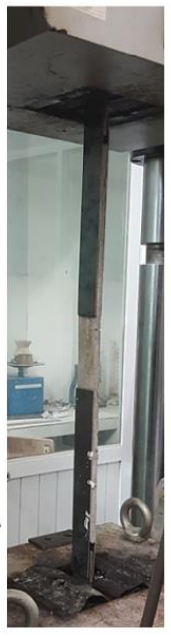

c) Tensile test

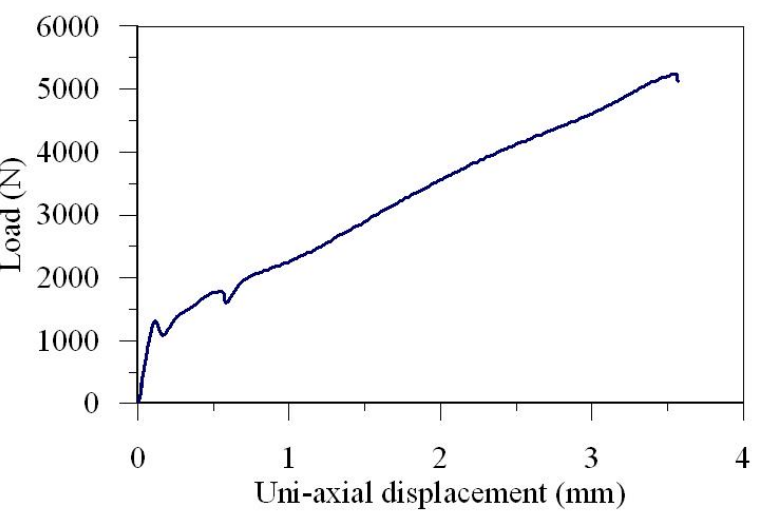

d) Typical load-displacement curve in tensile test

Figure 3. Carbon textile and TRC specimen for the uni-axial tensile test 
In this study, for textile reinforcement, carbon fiber textile SITgrid017 made from V.FRAAS Company (Germany) was used. The carbon fiber yarns, having a count of 3200 tex, were processed in the warp and weft directions with a distance of approximately $12.7 \mathrm{~mm}$ between them. Each carbon roving consists of 48.000 fibers and has a cross sectional area of $1.808 \mathrm{~mm}^{2}$ (in both directions), corresponding to $142 \mathrm{~mm} / \mathrm{m}$. According to recommendation of RILEM TC 232-TDT [12], the tensile strength of the fiber was measured by means of uni-axial tensile tests on the specimen with dimensions of $8 \times 25 \times 600 \mathrm{~mm}$ (Figure 3). In manufacturing the specimen, first a 4-mm thick layer of the FGC was applied, then a layer of textile was placed and lightly pushed into the first layer of matrix. Eventually the top layer of FGC was applied to form the surface of the specimen. Four steel tabs were attached to the ends of each coupon with high strength epoxy. The averaged tensile strength and elastic modulus of textile reinforcement were equal to $2890 \mathrm{MPa}$ and $185 \mathrm{GPa}$, respectively. The typical load-displacement curve in tensile test is also displayed in Figure 3-d. The test results indicated that TRC plate exhibit distinct strain-hardening behavior, with the classic threestages, including: un-cracked stage, crack stabilization stage, and failure stage.

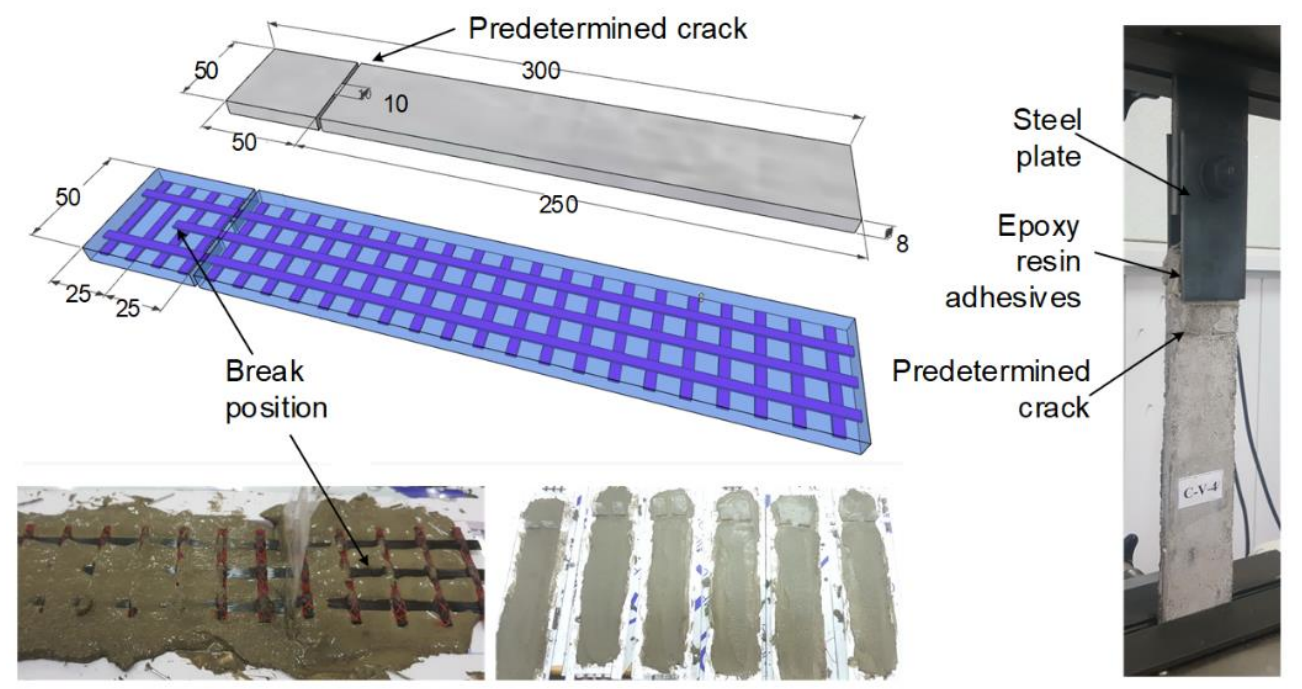

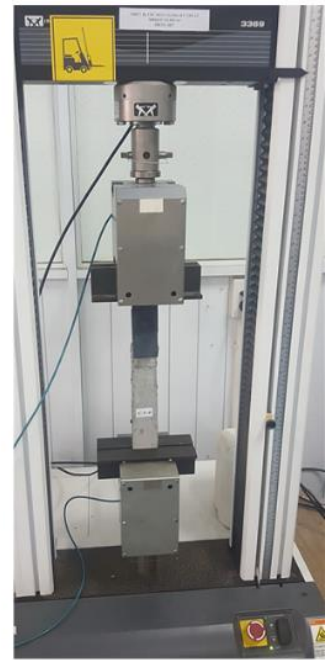

Pull-out test

Figure 4. Specimen for pull-out test

The bond behaviour between textile reinforcement and fine grained concrete is very important for the whole load bearing behaviour of the TRC structures. Following the test guideline of Zulassung Z-31.10-182 [13], one-layer reinforced specimens measuring $300 \times 50 \times 8 \mathrm{~mm}$ with a predetermined crack is prepared. The upper anchoring length $l_{E, 0}$ necessary for the examination of the bond characteristics is chosen. Per specimen, exactly one roving with embedding length of $l_{E, 0}=25 \mathrm{~mm}$ can be gradually pulled out from the fine grained concrete (Figure 4). By using the steel plate connection with epoxy resin in the upper load transfer plates, a direct lateral pressure onto the examined roving is avoided. The anchoring length of $250 \mathrm{~mm}$ chosen in the lower part of the specimen is sufficient for the securing of the anchoring. The average bonding strength between SITgrid017 textile and fine grained concrete was $18.8 \mathrm{~N} / \mathrm{mm}$ (force per length). Based on the tested results, the effective anchorage length of textile in fine grained concrete can be calculated as about $275 \mathrm{~mm}$

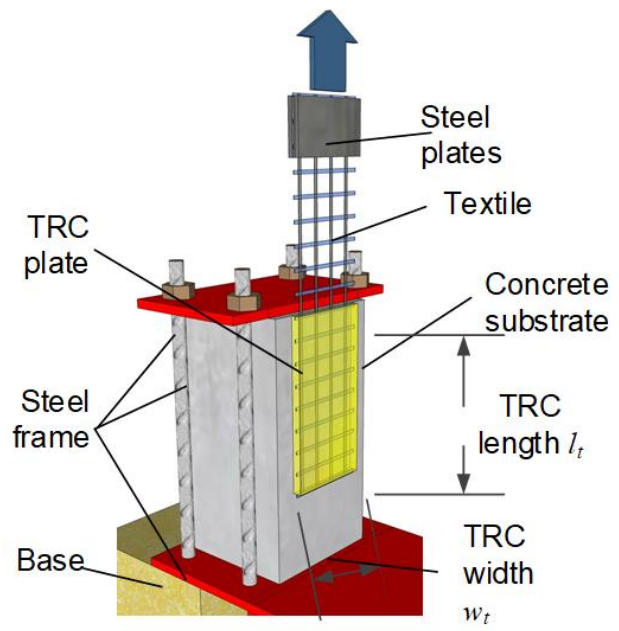

Figure 5. Test setup for determining interfacial bonding strength between TRC and substrate concrete 
In this research program, the interfacial behavior between TRC and substrate concrete was also studied by single lap pull-out test. Each specimen comprised RC prisms connected by TRC layer was tested (Figure 5), according to the instruction of RILEM Technical Committee 250-CSM [14]. The parametric study included the investigation of the TRC bond length, the number of textile layers and concrete surface preparation. The averaged bonding strength between TRC and substrate concrete was approximately 4.8 $\mathrm{MPa}$.

\subsection{Specimens Preparation and Test Setup}

The reinforcement cage was assembled separately outside and then placed inside the formwork. The concrete used to manufacture all columns was mixed, cast and cured in the laboratory. In order to achieve the desired composite action between the RC columns and the strengthening system, the surfaces were roughened and the corners were grinded using a grinding wheel (Figure 6). Then, four columns were strengthened in form of full jackets. The first applied layer of FGC was $5 \mathrm{~mm}$ thick, to provide an even surface for the carbon textile and to fill any underlying voids. It should be noted that, the thickness of FGC at the corners was greater than $5 \mathrm{~mm}$. The textile was then pressed slightly into the FGC until the FGC protruded out of the perforations between the rovings. The second FGC layer was then applied to completely cover the textile fabric and the procedure was repeated for each layer of TRC. The overlap length of textile was pressed into the added FGC layer to ensure proper bond. To prevent local failure of at two ends of columns under compressive loading, two steel plate boxes was bonded and welded after finishing strengthened works. These boxes were capped to prevent concrete crushing and to ensure an even transfer of load over the concrete surface during the test. These capped boxes at the top and bottom faces of the columns also needed to be flat and parallel to avoid stress concentrations and non-uniform loading conditions.

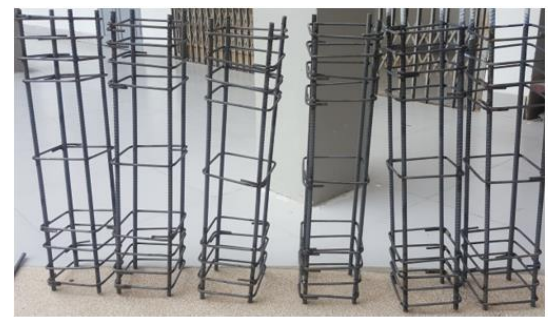

The reinforcement cages

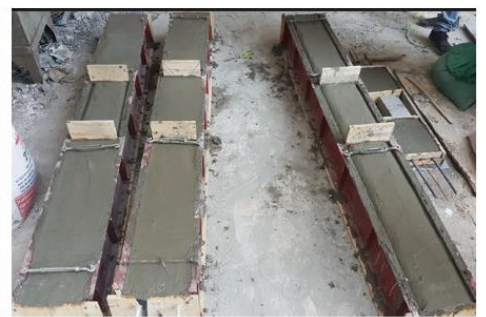

Casting RC columns

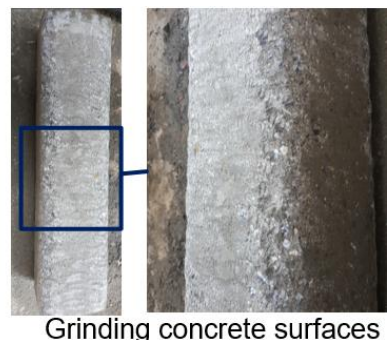
and conners
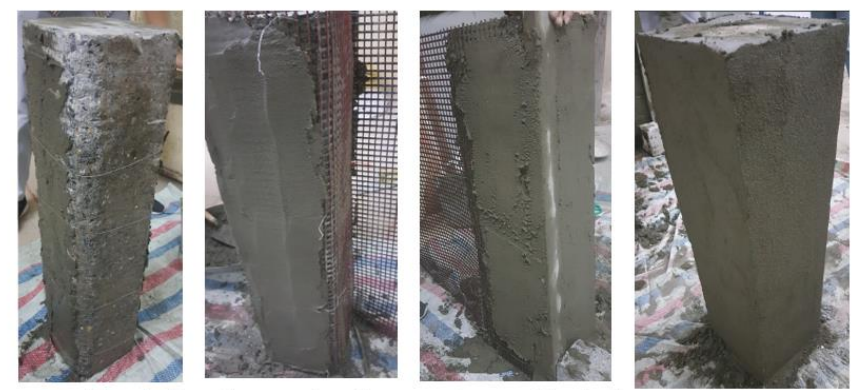

Plastering fine grained concrete and jacketing textile layers

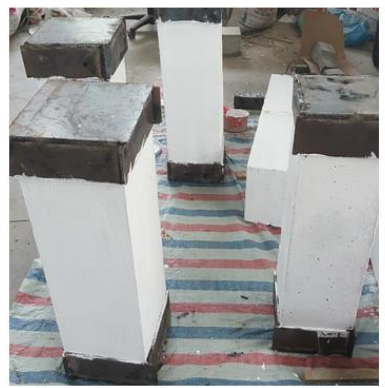

Capping steel boxes at two ends of specimens

Figure 6. Casting RC column and strengthening procedures with carbon TRC jackets



LVDT 3

SG 4

SG 3

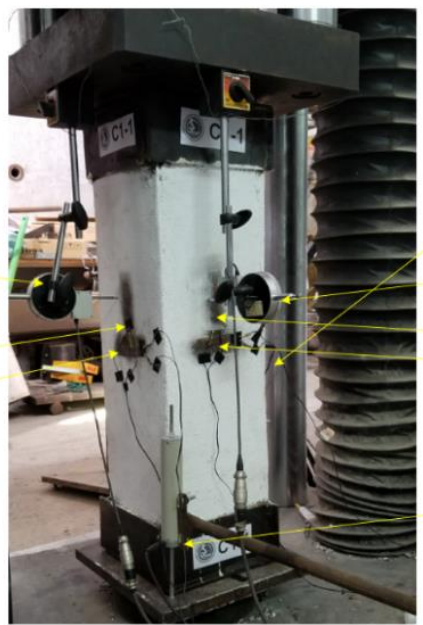

LVDT 2

LVDT 4

SG 2

SG 1

Figure 7. Test setup 
All tests were conducted in the Structural Engineering Laboratory at University of Transport and Communications, Vietnam. The columns were subjected to a monotonically increasing concentric uniaxial compression load, using a SANS Universal Testing Machine with a capacity of $3000 \mathrm{kN}$. All columns were tested using force controlled method, with loading rate of $1 \mathrm{kN}$ per second. Uniaxial electrical resistance strain gauges were applied to the surfaces of the columns. Two strain-gages were applied to each face of the column at mid-height in the longitudinal direction and transverse direction, as shown in Figure 7. At each surface, two LVDTs were installed on surface of the columns for both longitudinal and transverse direction, to measure their displacement during the test.

\subsection{Test Results and Discussion}

Applied load vs. axial displacement curves for six specimens are shown in Figure 8. The test results of all specimens are summarized in Table 1. Images depicting the failure mode of specimens are Figures 9, 11, and 12. The longitudinal strain and transverse strain values at the mid height of the column were recorded. Load-strain diagrams were plotted for the all columns, as shown in Figure 10. In general, the C1-1, C1-2, C2-1 and C2-2 jacketed column specimens showed a significant increase in ultimate load carrying capacity than the reference columns.

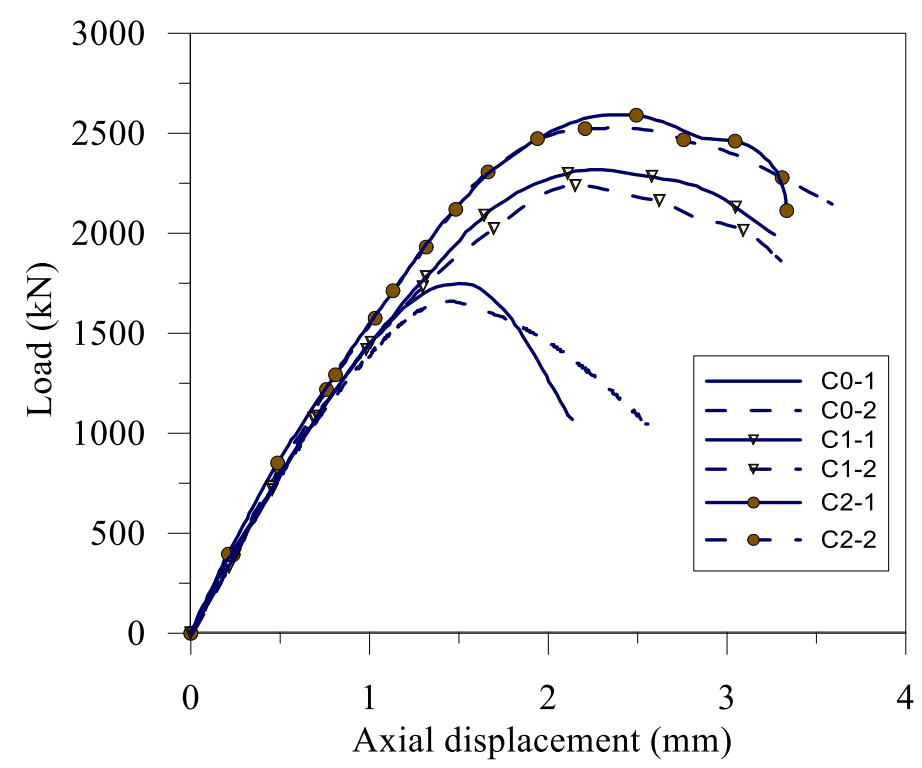

Figure 8. Applied load - axial displacement of tested columns

The experimental testing began with the control columns C0-1 and C0-2. Regarding to the load - axial displacement of both control columns, the initial responses were linear. The first visible crack appeared on the surface when columns reached approximately $74 \%$ of their predicted peak load. The load continued increasing with a decreased slope value until it reaches the failure point. Table 1 shows that the average ultimate load carrying capacity of $\mathrm{RC}$ reference column was $1720.36 \mathrm{kN}$, where the axial displacement was $1.52 \mathrm{~mm}$. After the peak load, the response curves declined rapidly due to the brittle failure of the RC columns. The failure mode of control specimens was brittle, indicated by wide longitudinal cracks along the full length of each column face. After that, the concrete cover started to spall off followed by crushing of concrete and buckling of longitudinal rebars (Figure 9). Testing was terminated when portions of the RC column began to break off from the core. Figure 10 shows the load-strain diagrams of control column $\mathrm{C} 0-1$, with a maximum longitudinal strain of $3.2 \%$ at failure point. The corresponding value of transverse strain in $\mathrm{C} 0-1$ surface was $2.4 \%$.

Table 1. Ultimate loads and calculated strengthening effectiveness

\begin{tabular}{|c|c|c|c|c|c|c|c|c|c|}
\hline \multirow{2}{*}{ Column } & \multicolumn{2}{|c|}{$\begin{array}{c}\text { Column section with } \\
\text { strengthening layers }(\mathrm{mm})\end{array}$} & \multicolumn{2}{|c|}{ Ultimate load (kN) } & \multicolumn{2}{|c|}{$\begin{array}{c}\text { Energy dissipation } \\
(\mathrm{kNmm})\end{array}$} & \multicolumn{3}{|c|}{ Strengthening effectiveness } \\
\hline & Width & Height & $\boldsymbol{P}_{i}$ & $\boldsymbol{P}_{a v g}$ & $E_{i}$ & $\boldsymbol{E}_{a v g}$ & $\begin{array}{c}\text { Strengthen in } \\
\text { ultimate load }(\%)\end{array}$ & $\begin{array}{l}\text { Confined } \\
\text { effect }(\%)\end{array}$ & $\begin{array}{l}\text { Strengthen in energy } \\
\text { dissipation }(\%)\end{array}$ \\
\hline $\mathrm{C} 0-1$ & \multirow{2}{*}{200} & \multirow{2}{*}{200} & 1755.49 & \multirow{2}{*}{1720.37} & 2542.81 & \multirow{2}{*}{2785.37} & \multirow{2}{*}{ - } & \multirow{2}{*}{-} & \multirow[b]{2}{*}{ - } \\
\hline $\mathrm{C} 0-2$ & & & 1685.25 & & 3027.93 & & & & \\
\hline C1-1 & \multirow{2}{*}{220} & \multirow{2}{*}{225} & 2215.67 & \multirow{2}{*}{2267.75} & 5519.32 & \multirow{2}{*}{5456.04} & \multirow{2}{*}{31.82} & \multirow{2}{*}{13.39} & \multirow{2}{*}{95.88} \\
\hline $\mathrm{C} 1-2$ & & & 2319.84 & & 5392.75 & & & & \\
\hline $\mathrm{C} 1-1$ & \multirow{2}{*}{230} & \multirow{2}{*}{235} & 2456.96 & \multirow{2}{*}{2493.77} & 6744.33 & \multirow{2}{*}{6523.61} & \multirow{2}{*}{44.96} & \multirow{2}{*}{17.71} & \multirow{2}{*}{134.21} \\
\hline $\mathrm{C} 2-2$ & & & 2530.58 & & 6302.89 & & & & \\
\hline
\end{tabular}


Both C1-1 and C1-2 columns were wrapped with one layer of carbon textile. Figure 5 shows the axial load-axial displacement behaviour of C1-1 and C1-2 specimens. It can be seen that before ultimate points, no significant change in behavior between the strengthened and control specimens was observed. However, columns wrapped by TRC provided a slightly higher initial stiffness, due to the extension in column section. The load - axial deformation curve for C1-1 rose steadily from zero and the first cracks appeared at a displacement of $0.97 \mathrm{~mm}$. First cracks were observed approximately $150 \mathrm{~mm}$ from the top and bottom of the column specimens. Then, the curve kept rising with a lower-value slope until hitting the ultimate point at which the load reached $2224 \mathrm{kN}$ and the displacement was 2.39 $\mathrm{mm}$. After the ultimate load, the descending branch was non-linear and had a gradual slope, characterized by a larger deformation, with respect to unreinforced cases. Columns wrapped by CTRC showed the effect of confinement, indicating an increase in column ductility.

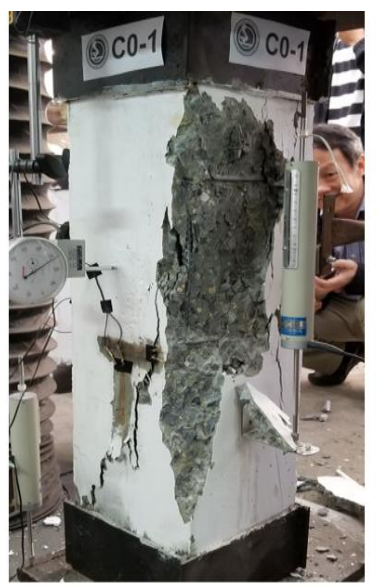

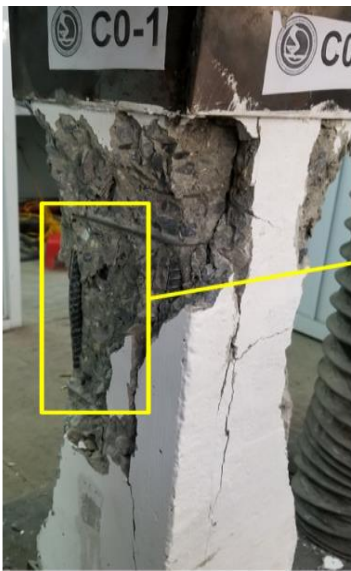

C0-1

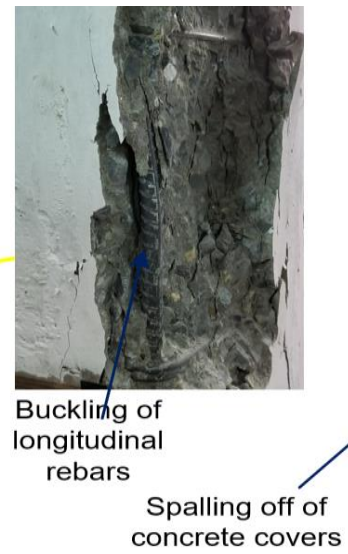

concrete covers

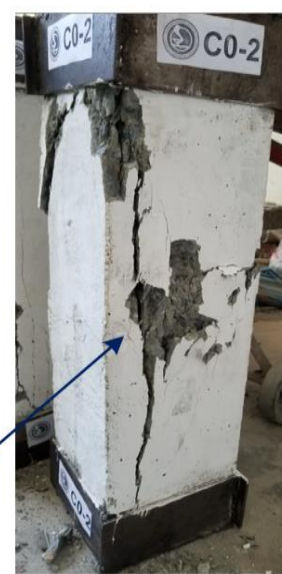

C0-2



Buckling of longitudinal rebars and crushing of concrete

Figure 9. Cracks pattern of control columns $\mathrm{CO}-1$ and $\mathrm{CO}-2$

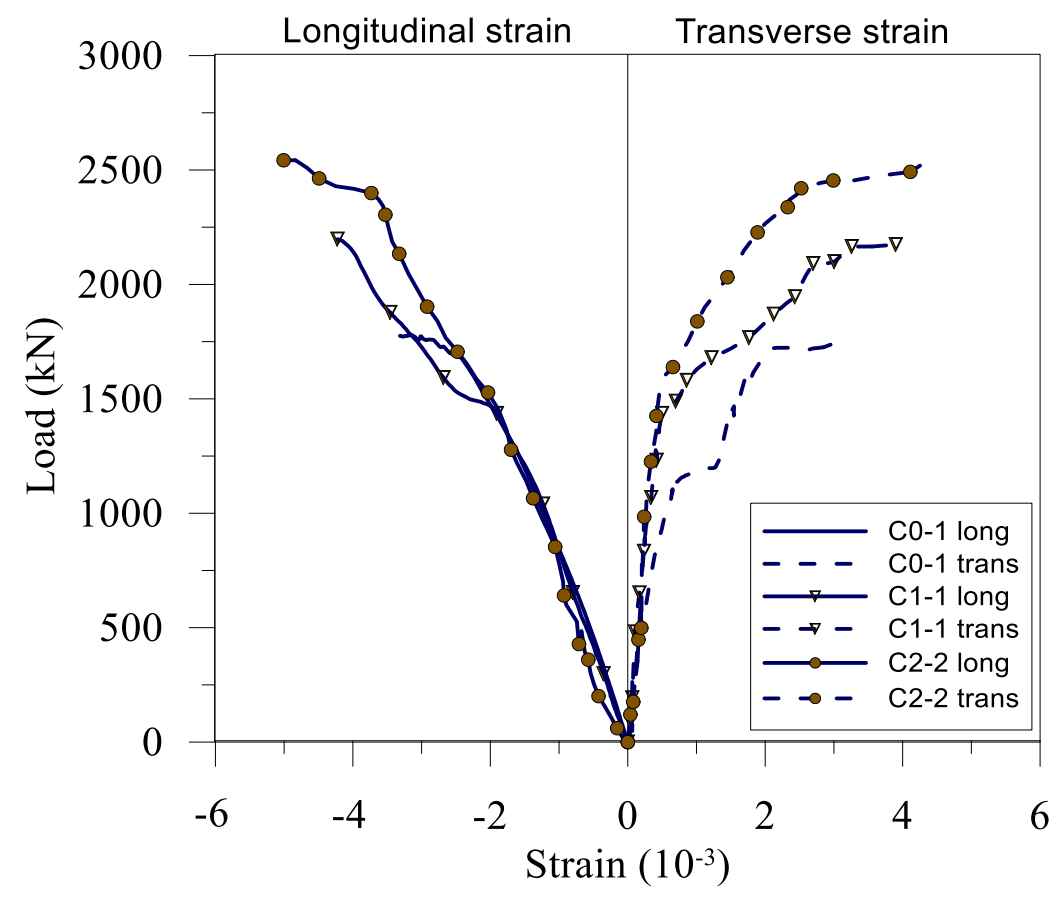

Figure 10. Load - strains relationship of test specimens

Table 1 revealed that there is a significant increase of $31.82 \%$ in ultimate load carrying capacity of C1-1 and C1-2 jacketed columns with respect to control columns. The obtained load increase is the result of two parts: the load bearing provided by the fine grained concrete layer and confinement effect enable by textile reinforcement. The first part of load increase could be attributed to the effective cross sectional area of the fine-grained concrete, which is calculated from the fine-grained concrete layer minus the textile reinforcement area. According to the simple model of Ortlepp et.al [15], in order to calculate the normal force participation of the FGC layer, a reduction factor of 0.75 was taken for compressive strength of FGC. It can be explained that, each single textile rovings can be regarded as holelike volumes inside the FGC which cause stress concentrations at the hole locations. By calculation, the axial force 
participation of the FGC layer was $316.8 \mathrm{kN}$. Consequently, the improved load of $230 \mathrm{kN}$ can be attributed to the confinement caused by the textile reinforcement. Thus, the load increase in C1-1 and C1-2 columns was composed of approximately $57.9 \%$ strengthening effect due to the normal force participation of the FGC layer and approximately $42.1 \%$ confinement effect of the carbon textile reinforcement. It can be seen from Figure 10, C1-1 jacketed column specimen has gained an increase in the longitudinal axial strain at rupture with respect to control columns. The longitudinal strains of C1-1 specimens were 3.7-4.2\%, while the transverse strains ranged from 3.3 to $3.8 \%$.

The failure is initiated by vertical "hairline" cracks at the middle part of the strengthened columns. The vertical hairline cracks of the C1-1 and C1-2 specimens are become visible at the point where applied load reach $75 \%$ to $80 \%$ of the ultimate load. After the ultimate load was reached, the vertical cracks along the overlap widened significantly. The number and width of these cracks increased with the increase in the axial load until the specimen reached its failure load. The failure mode of $\mathrm{C} 1-1$ and $\mathrm{C} 1-2$ specimens was sudden, corresponded to the tensile rupture of transverse rovings after the formation of longitudinal cracks near the corners. Testing was terminated after the transverse rovings in the corners broke completely (see Figure 11), causing a rapid decrease in the applied load. Compare to the related works from the literature ([7] and [15]), the strengthened columns have similar failure manner with the rupture of transverse textile in the corners of column.
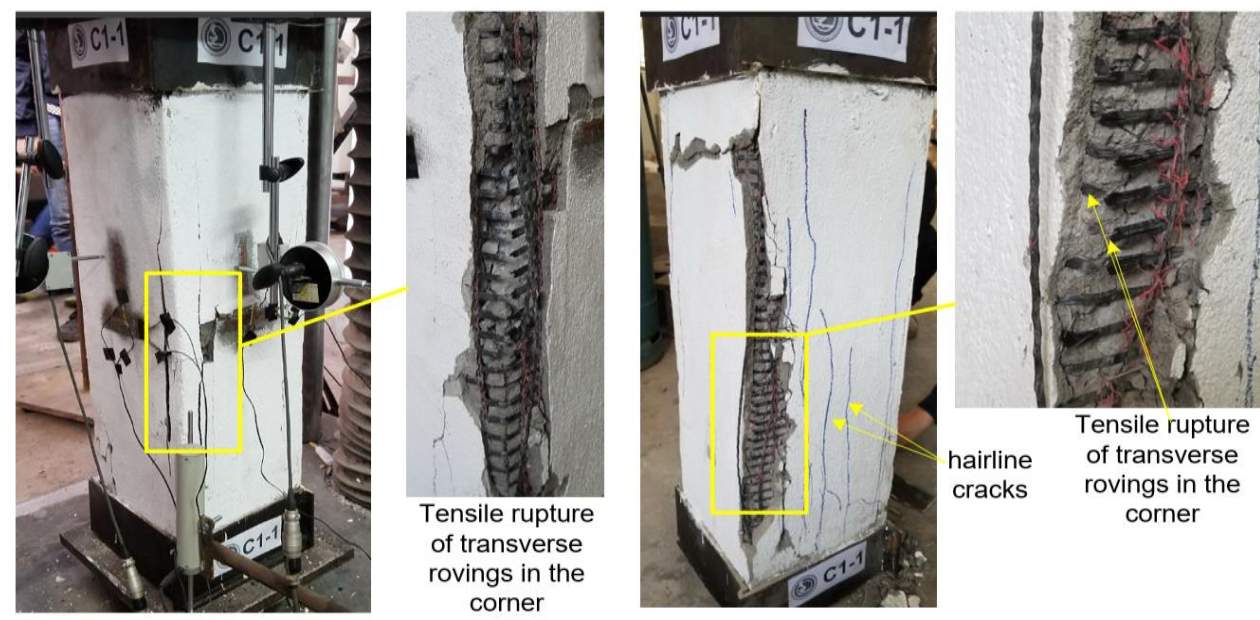

C1-1

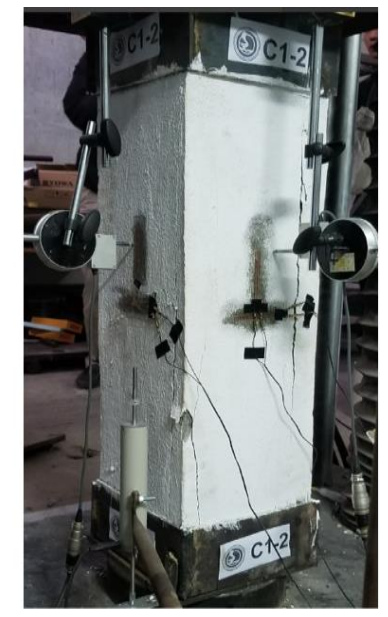

C1-2

Figure 11. Experimental failures of strengthened columns with 1 textile layer

It can be seen from Figure 8 and Table 1 that, C2-1 and C2-2 specimens show a significant increase in both the load carrying capacity and the ductility. The load - axial deformation relations are nearly linear up to a haft of the ultimate load carrying capacity, beyond which the curves became nonlinear. Just before the peak load, small vertical cracks formed on the column faces, i.e., in the longitudinal direction of the column. Once the peak load was reached, the cracks widened and became apparent on all four column faces. Both columns failed suddenly due to rupture of the carbon TRC jacket together with a loud explosion. Compare to control columns, the increases in ultimate capacity of the strengthened columns were $42.8 \%$ in $\mathrm{C} 2-1$ and $47.1 \%$ in $\mathrm{C} 2-2$. The calculation shows that, in this load capacity enhancement, $60.6 \%$ was attributed to fine grained concrete layer and $39.4 \%$ to the confinement effect. Figure 10 also presents the obtained load strain diagrams of C2-2 column specimen. The load strain relations are nearly linear up to the load level of about $1500 \mathrm{kN}$. After this point, the transverse strains increased sharply, represent the cracks of fine grained concrete. The C2-2 column reached its ultimate load carrying capacities at axial strains of about 5\%, having transverse strains at rupture points of approximately 4.15\%. At failure, the longitudinal axial strain of C2-2 jacketed column specimen was 1.6 times the axial strains of control column $\mathrm{C} 0-1$. This comparison clearly shows the high longitudinal and transverse strains at fine grained concrete surfaces, which is explained by small elastic modulus. It is also noted that, elastic modulus of FGC is $17000 \mathrm{MPa}$, much smaller shows than the one of ordinary concrete with similar strength grades. Compare to the experimental results of Ortlepp et al. [15], which was used the fine grained concrete with higher elastic modulus, the obtained longitudinal and transverse strains were also larger. These useful results will increase the ductility of tested columns by keep activating confinement effect.

Specimens review after tests found no signs of adherence loss between columns and jacketing or debonding between textile rovings and fine grained concrete. The rupture of textile rovings always initiated in the proximity of a corner in the jacket. All four strengthened specimens experienced buckling of the internal steel reinforcement and crushing of concrete at failure, as discovered from post-test observation of the specimens. The rupture of textile rovings occurred in both $1^{\text {st }}$ and $2^{\text {nd }}$ layer of carbon textile, especially in the "weak part" of the column, where the stirrups were arranged at the spacing of $200 \mathrm{~mm}$. It is worth to mention that, increasing the number of wrapped textile layer resulted in the development of more minor cracks (hairline cracks) on the column surfaces. 


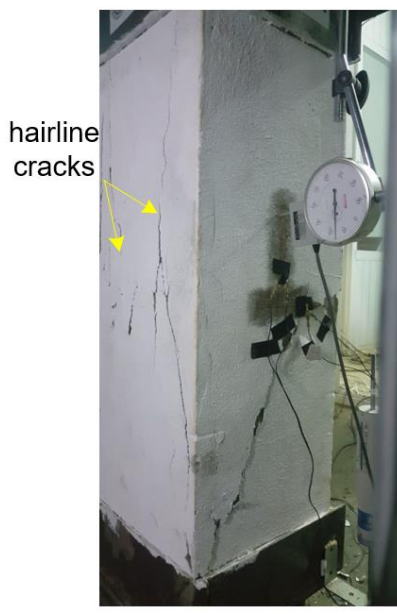

C2-1

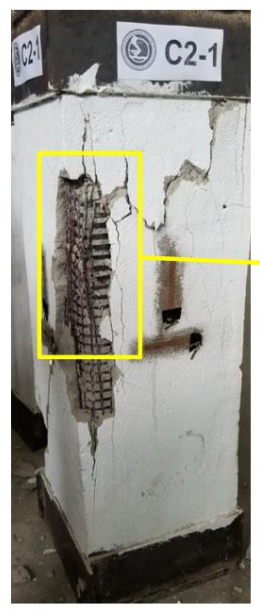

Figure 12. Failures in strengthened columns C2-1 and C2-2

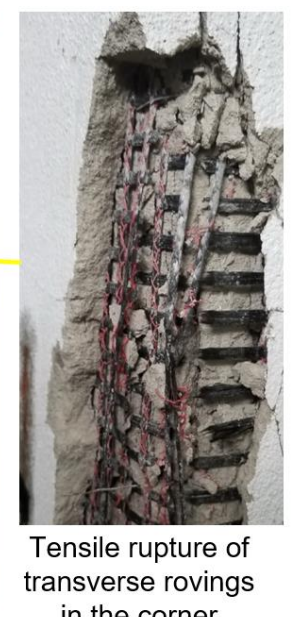

in the corner
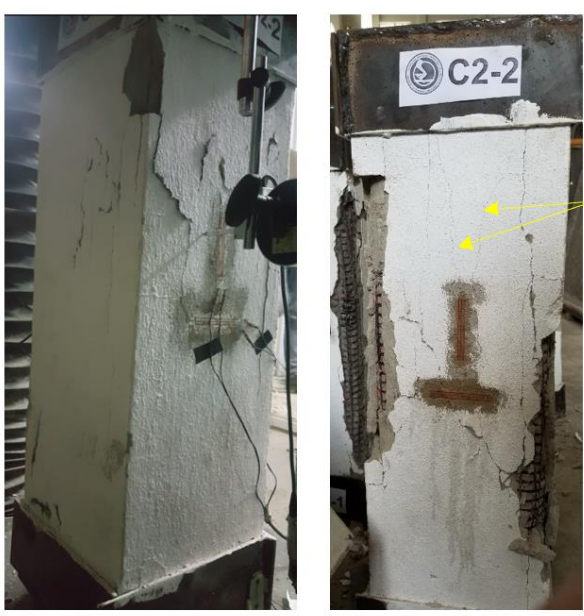

C2-2 hairline cracks

The total dissipated energy for the specimen is defined as the area enclosed under the load-displacement curve from the origin point to the failure load point. Table 1 also shows the value for each column tested under concentric load and the averaged dissipated energy for each group. Comparing with the control specimens, the combination of the fine grained concrete layer and confinement effect led to significant higher values of energy dissipation for the jacketed columns. The energy absorption capacity of the strengthened columns has increased by $95.88 \%$ with 1 textile layer and $134.21 \%$ with 2 textile layers.

\section{Finite Element Modeling}

\subsection{Modeling}

The behaviour of tested columns was simulated using ATENA, a robust FEM analysis software [16]. Because of the symmetry in both directions, one quarter of column sections was modelled by applying appropriate boundary conditions. The concrete parts of core columns and TRC layers were modelled with solid elements, brick type, while reinforcing bars and textile with truss elements - the reinforcement elements in ATENA. Only textile reinforcements perpendicular to the column axis were considered in the models. According to the experiments three analysis models were built: C0-FEM for reference column, C1-FEM for column strengthened by 1 TRC layer and C2-FEM for column strengthened by 2 TRC layers.

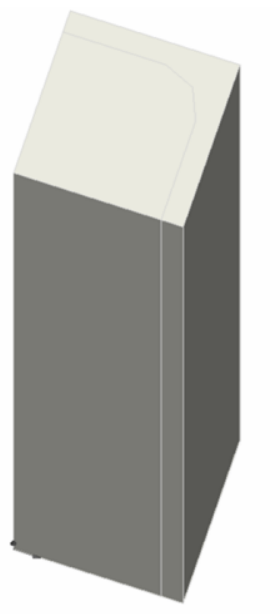

The whole quarter model

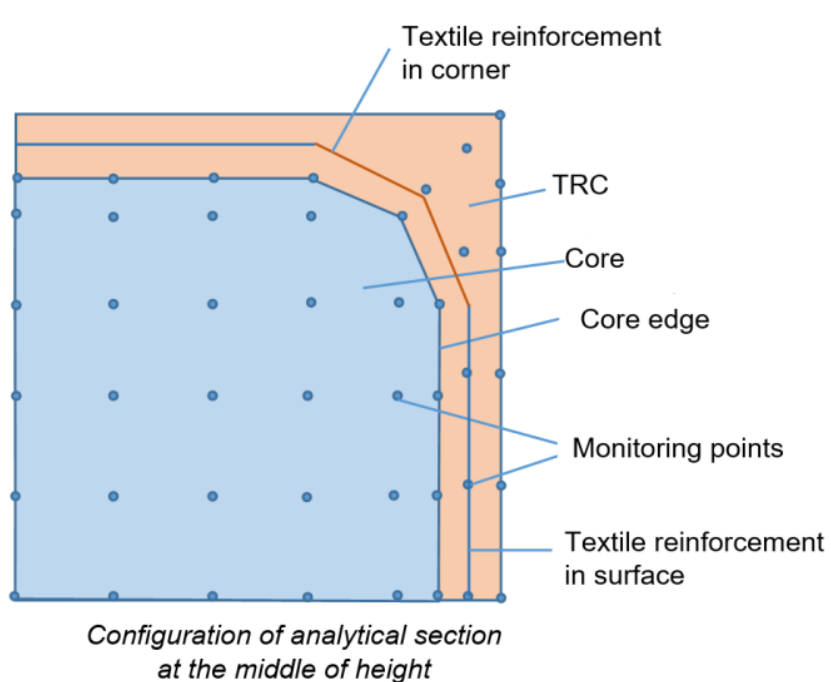

at the middle of height

Figure 13. ATENA model for strengthened column C1-FEM

As constitutive model for concrete of core columns and TRC layers, CC3DNonLinCementitious2, one of the builtin models of ATENA, was applied. However, some parameters of this material model were adapted based on suggestions of Vassilis et al. [17] as well as on results of an intensive parameter study. Furthermore, according to Ortlepp et al. [15], the analytical strength of the fine-grained concrete in TRC layer is reduced to 0.75 its tested 
strength. For steel reinforcements, bi-linear model is used with yield strength of $425 \mathrm{MPa}$ and E-modulus of $200 \mathrm{GPa}$, while the multilinear model was used for textile with the tensile strength of $2890 \mathrm{MPa}$, E-modulus of $185 \mathrm{GPa}$ and rupture strain of $15.6 \%$. However, in the corner regions, strength of textile reinforcements was reduced due to the sharp kink of roving caused by concentrated concrete expansion [15]. Based on the comparison between experimental and analytical results, the appropriate value for textile strength for the corner regions was found of $1200 \mathrm{MPa}$. Some detail parameters of concrete materials in the analysis models are listed in Table 2 and Table 3.

Table 2. Parameters of ordinary concrete

\begin{tabular}{lclc}
\hline Parameter & Value & Parameter & Value \\
\hline Compressive Strength, $\boldsymbol{f}_{c}^{\prime}(\mathrm{MPa})$ & 39.5 & Plastic strain at compressive strength, $e_{c p}$ & 0.0008 \\
E-modulus, $\boldsymbol{E}_{\boldsymbol{c}}(\mathrm{GPa})$ & 29 & Failure surface eccentricity, $e$ & 0.52 \\
Poisson's ratio, $\boldsymbol{u}$ & 0.2 & Multiplier for the plastic flow direction, $b$ & 0.50 \\
\hline
\end{tabular}

Table 3. Parameters of fine-grained concrete

\begin{tabular}{lclc}
\hline Parameter & Value & Parameter & Value \\
\hline Compressive Strength, $\boldsymbol{f}_{\boldsymbol{c}}^{\prime}(\mathrm{MPa})$ & 33 & Plastic strain at compressive strength, $e_{c p}$ & 0.0025 \\
E-modulus, $\boldsymbol{E}_{\boldsymbol{c}}(\mathrm{GPa})$ & 17 & Failure surface eccentricity, $e$ & 0.52 \\
Poisson's ratio, $\boldsymbol{u}$ & 0.2 & Multiplier for the plastic flow direction, $b$ & 0 \\
\hline
\end{tabular}

The bond between concrete and the reinforcing bars as well as textile fiber is defined as "Perfect Connection". The contact of TRC layers and core concrete is also modelled as "perfect connection". Load is applied on the top surfaces of macros presenting the core and TRC layers. The analysis parameters are "Standard Newton - Raphson", the default option of ATENA. In order to get the analysis results during the analysis process, many "monitoring points" are located in the interested position. They are included the displacement of the top, the reaction of the bottom, strain and stress of section center, of points at core edges and section edges as well as corners. In order to obtain the detailed results, many points were added to the section at middle height. Textile reinforcements elements were divided into two parts, "textile reinforcement in corner" and "textile reinforcement in surface" to assign appropriate strength values (Figure 13).

\subsection{Results Analysis}

Comparative plots of the simulated load - displacement for the analyzed column models are presented in Figure 14a. In order to verify the FE models, the numerical and experimental load-deflection curves are also compared with each other and illustrated in Figure 14-b. Generally, the simulated results agree very well with the experimental data. The ultimate load in strengthened column models are marginally smaller than those at tested columns, corresponding to a difference of $1.66 \%$ and $2.76 \%$ in C1-FEM and C2-FEM, respectively.

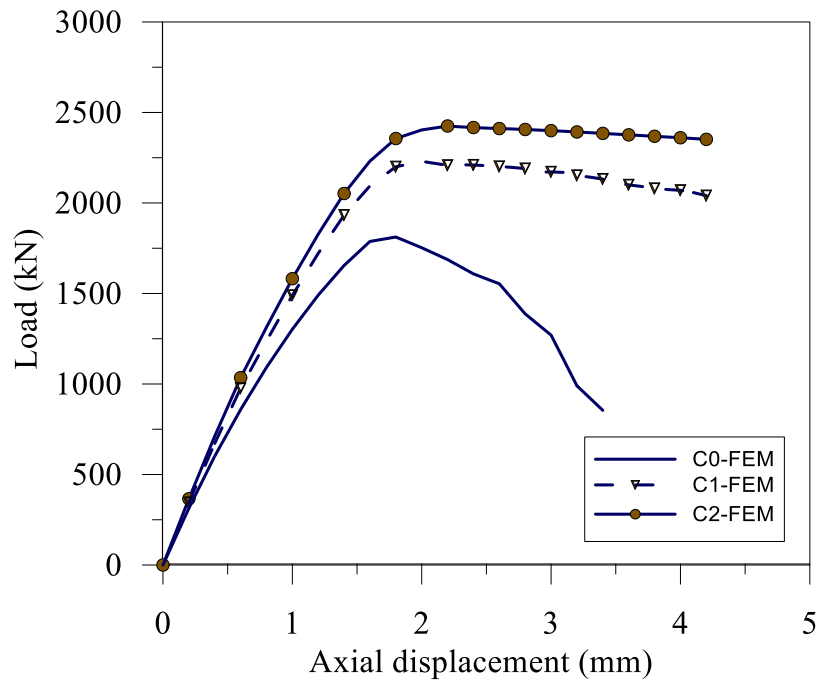

a) Numerical results

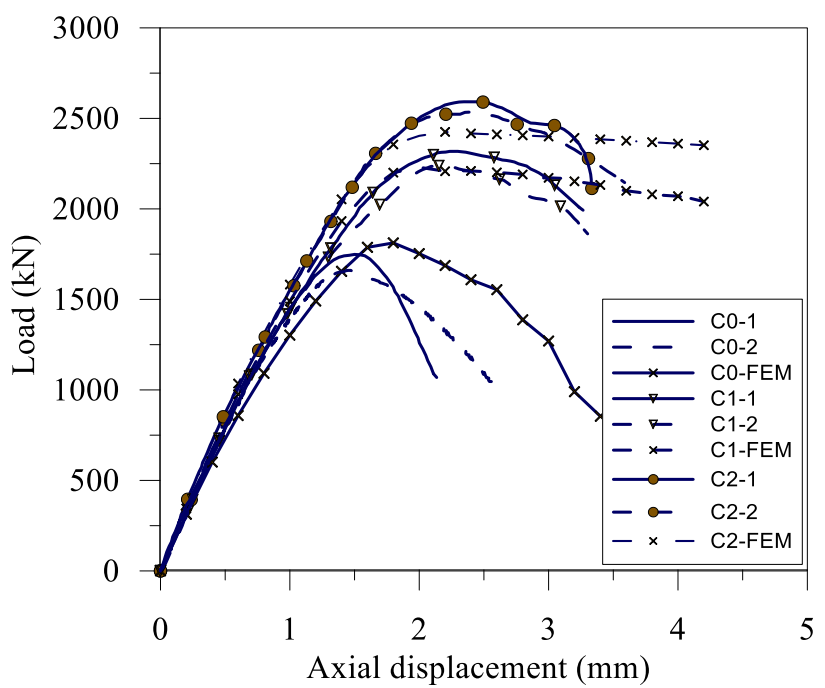

b) Comparison between experimental and numerical results

Figure 14. Load - displacement response of columns 
The axial load-strains curves corresponding to each of the models are shown in Figure 14. For each models, two monitoring points at center and "core edge" were selected to obtain the strain values in longitudinal and transverse direction. The differences between simulated and experimental values in the load strain relationships can be explained by the appearance of cracks at the location of bonded strain-gages. Figure 15 also shows that transverse strain of column $\mathrm{C} 1$ and $\mathrm{C} 2$ starts to expand rapidly at the point at which the reference column reaches the peak load. It means that, from this point upward, the core concrete exhibits large plastic strain and the confinement effect provided by textile reinforcement will be activated.

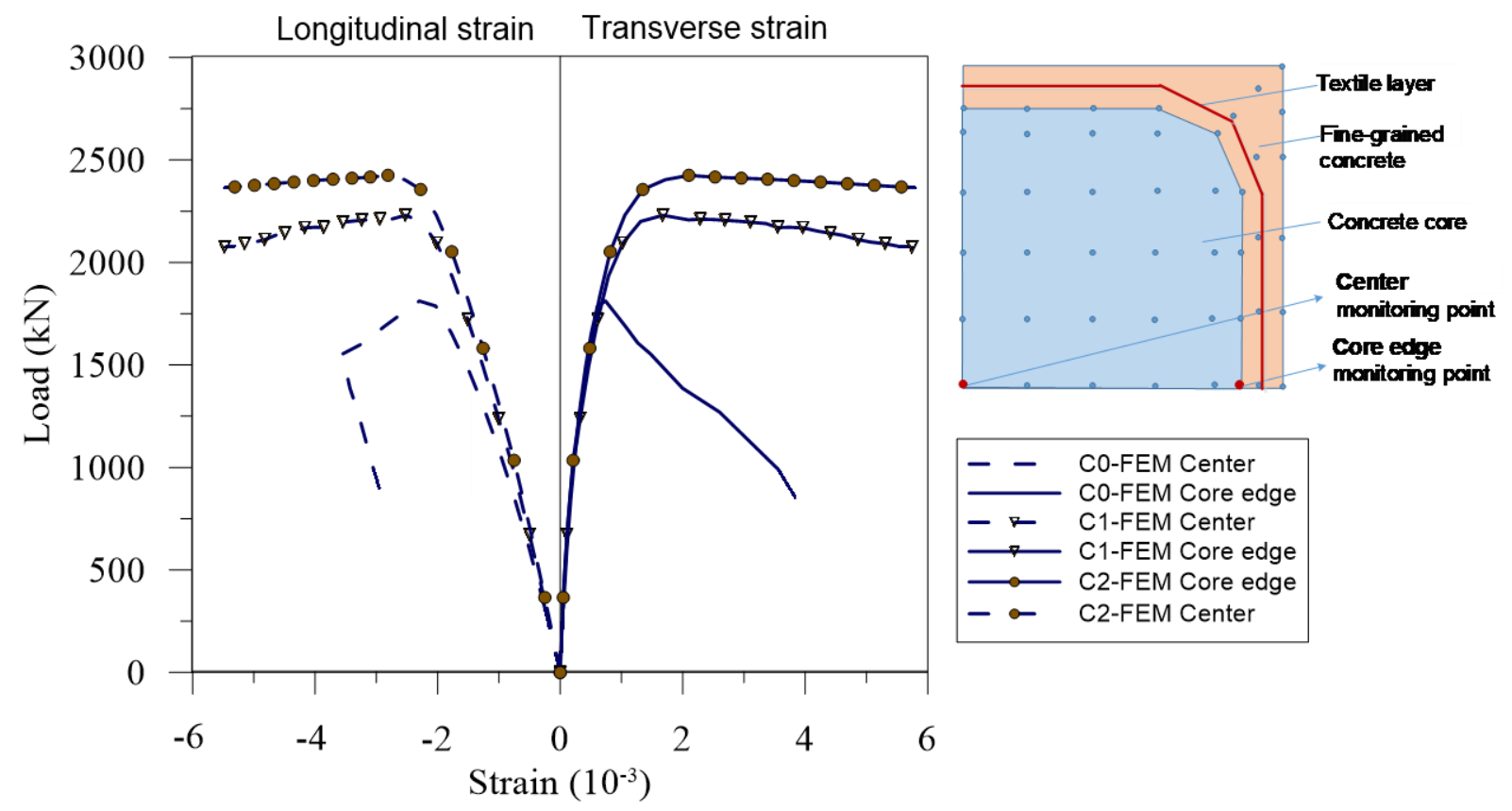

Figure 15. Load - strains response of FEM columns

The confinement effect by mean of middle principal stresses is shown in

Figure 16 for strengthened columns C1-FEM and C2-FEM. The confinement stresses were obtained along core edge of the middle height section for three stages, including: concrete core peak load, column peak load and column failure. The corresponding average confinement stresses were calculated and listed in Table 4 . In the whole quarter section, the confinement stresses are displayed as scalar diagram in Figure 17-a-b. It can be seen that this stress is concentrated near the column corner. It is worth mentioning that, full tensile capacity of the textiles cannot be used because of the complexity in stresses distribution in these areas. The loss in tensile strength of textile reinforcements are related to the lateral pressure and the bending stresses of the filaments at the crack edges. The cracking of the concrete along the reinforcement also leads to damage to the rovings and causes a decreasing strength of the component. Thus, the concentration of confinement stress in the corner is another cause to strength reduction of textile reinforcement.

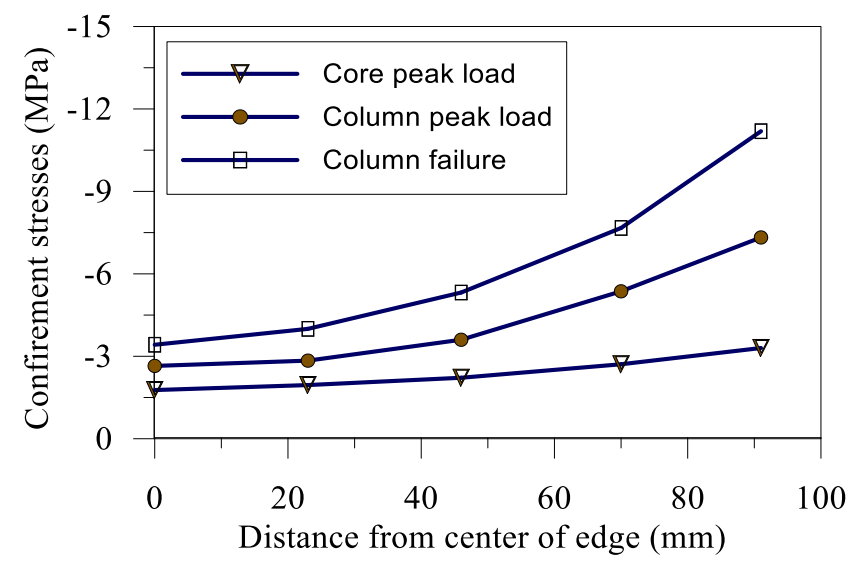

a) Column C1-FEM

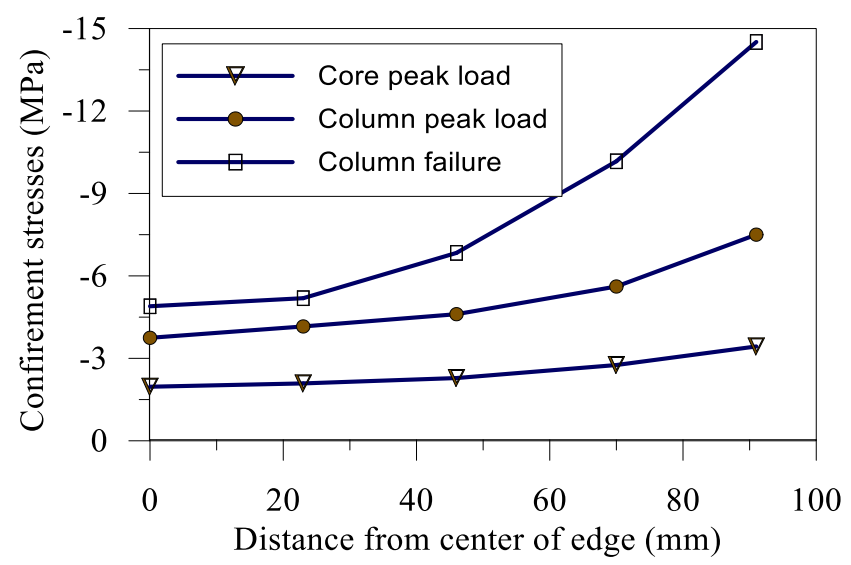

b) Column C2-FEM

Figure 16. Distribution of confinement stress a long core edge of column C1-FEM and C2-FEM 
Table 4. Average confinement stresses

\begin{tabular}{cccc}
\hline Column & $\begin{array}{c}\text { Confinement stress at failure of } \\
\text { core concrete (MPa) }\end{array}$ & $\begin{array}{c}\text { Confinement stress at maximal load } \\
\text { (MPa) }\end{array}$ & $\begin{array}{c}\text { Confinement stress at column } \\
\text { failure (MPa) }\end{array}$ \\
\hline C1-FEM & 2.34 & 4.15 & 6.00 \\
C2-FEM & 2.44 & 4.97 & 7.88 \\
\hline
\end{tabular}

The distribution of axial stress of quarter section of columns at peak load is shown in Figure 18-a-b. For column C1-FEM, the axial stress changes in the range of $42 \mathrm{MPa}$ and $48 \mathrm{MPa}$, while for column C2-FEM, the range is of 44 $\mathrm{MPa}$ and $50 \mathrm{MPa}$. Such, thanks to the confinement effect enable by TRC, the maximal compressive axial stress in column core can be $25 \%$ higher the than concrete strength. These figures also show that the highest axial stress is concentrate at the corner regions. From these figures, it can be seen that corner regions of sections are subjected to a complicated 3D stress state.

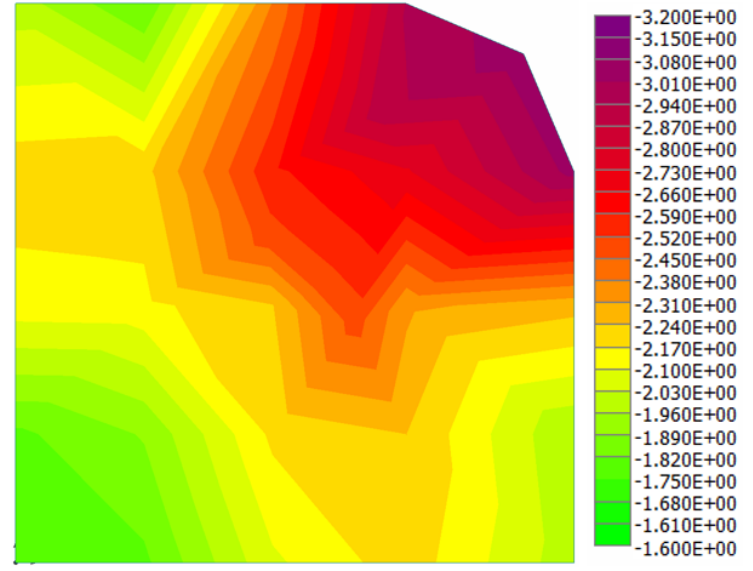

a) Confinement stress in column C1-FEM at peak load

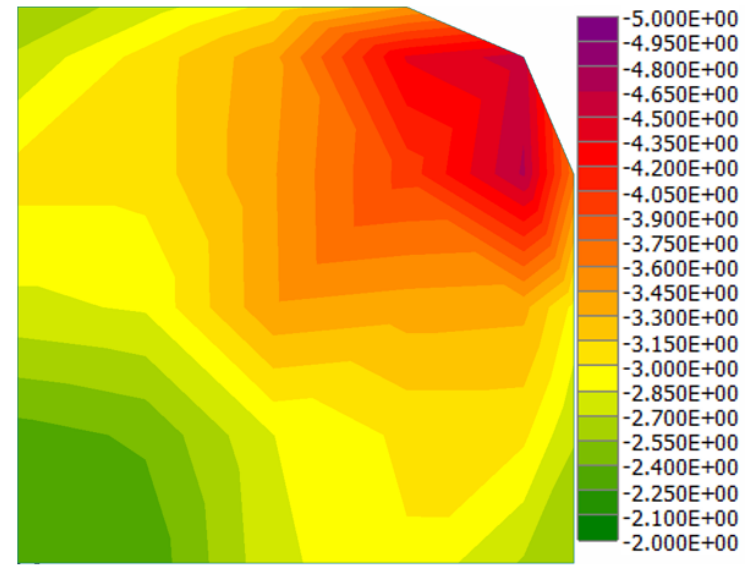

b) Confinement stress in column C2-FEM at peak load

Figure 17. Confinement stress distribution in strengthened columns C1-FEM and C2-FEM

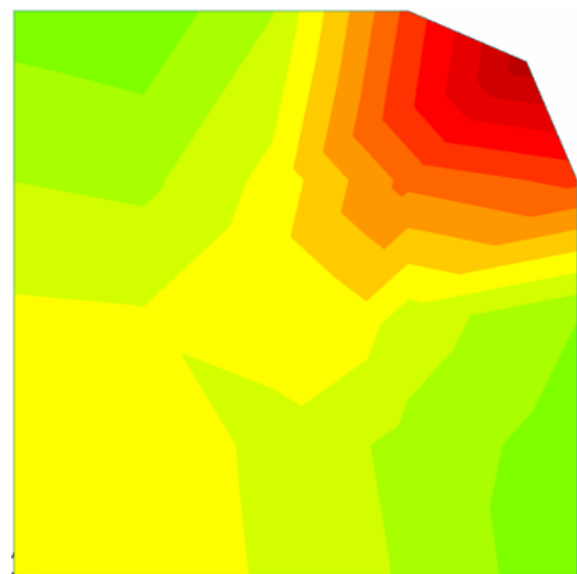

a) Axial stress in column C1-FEM at peak load

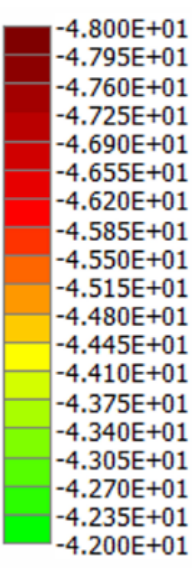

$200 \mathrm{E}+01$

Figure 18. Axial stress distribution in strengthened columns

The behaviour of textile in term of load-stress is presented in Figure 19. Normally, the stress in textile fibers lying in the corner regions is somewhat smaller than that in textile fiber at the edge. However, as can be seen from the experiment, textile reinforcement in corner regions teared earlier, which, in turn, leads to the abruptly failure of columns. Based on these facts, in the simulation models, the strength of textile reinforcement in such regions was reduced to obtain the closest resemblance to the experimental curve. The appropriate value for tensile strength of textile in the corner regions was found of approximately $1200 \mathrm{MPa}$. It can be seen in Figure 19, after reaching the tensile stress of approximately $1200 \mathrm{MPa}$, at the failure load level of strengthened columns, the stress in textile reinforcement in the corner regions drops immediately to zero, representing the rupture of textile. Compare to the original strength in the uni-axial tensile test, it can be assumed that the confined stress in the corner of the column reduced significantly the tensile failure strength of textile reinforcement. 


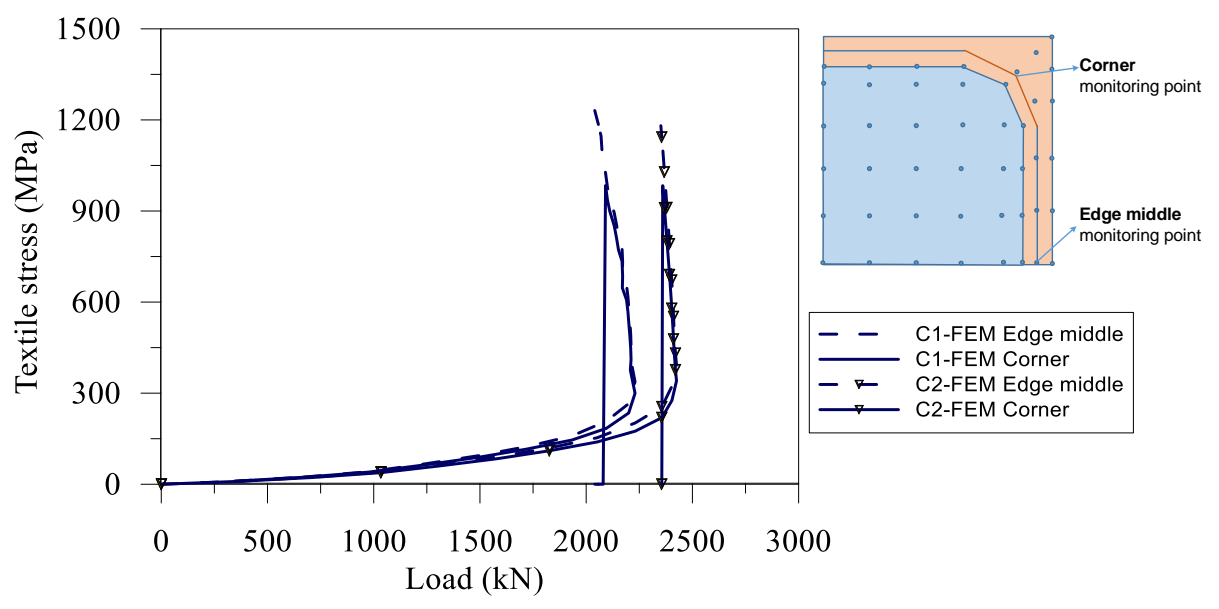

Figure 19. Load - tensile stress responses of textile

Figure 20 compared the deformation shape in numerical and experimental columns strengthened by 2 layers of textile. The failure modes from both experiment and program were almost identical with the peeling failure of the concrete cover in the corner. The failure mode of strengthened column C2-FEM was brittle, indicated by wide longitudinal cracks along the full length of each column face. After that, transverse textile rovings in "weak part" of the columns were broken, followed by crushing of concrete and buckling of longitudinal rebars.

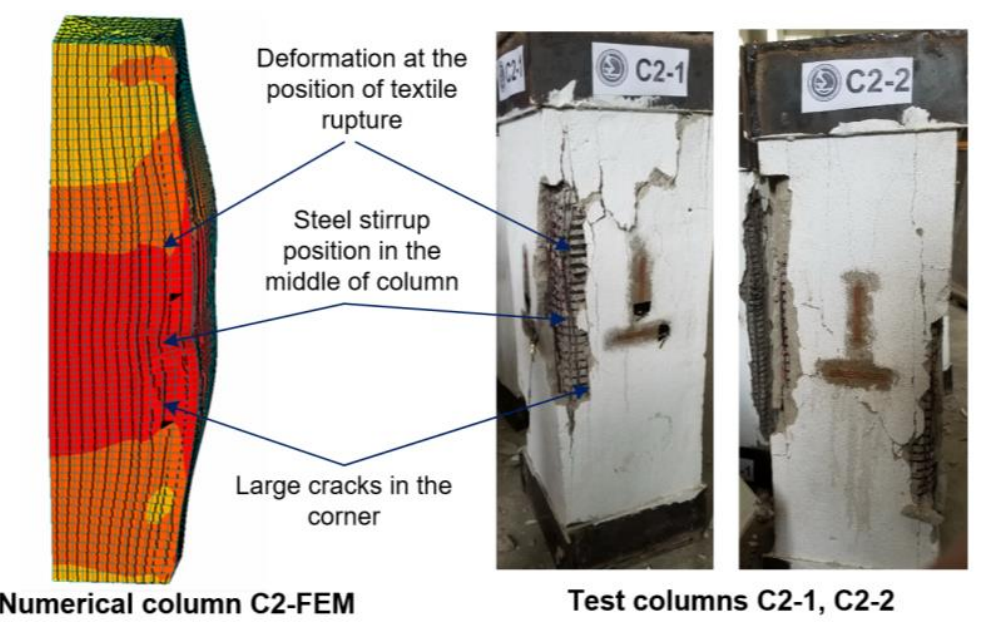

Figure 20. Failure deformation shapes in numerical and experimental columns

\section{Conclusion}

This paper presented both experimental and numerical investigations on the compressive behavior of RC columns strengthening by carbon TRC jacketing. Both the numerical and experimental results indicated that TRC is a reliable material for strengthening reinforced concrete structures. The experimental results show that TRC increased the strength of columns through enlarging the section area and the confining effect. The number of TRC layers increased, both strength and ductility of the specimens increased. The strength of specimens strengthened with one and two layers increased by $31.82 \%$ and $44.96 \%$ as comparing to the reference one, respectively. The strengthening with TRC layers also had as a result a large increase in the stiffness of the strengthened columns. Cracks appeared later in columns that were strengthened with bigger initial loading. Failure of all strengthened columns was together with tear of textile reinforcements at the column corners. The experimental results show the high longitudinal and transverse strains at fine grained concrete surfaces, which is explained by small elastic modulus. However, these useful results will increase the ductility of tested columns by keep activating confinement effect. The energy absorption capacity of the strengthened columns increased by $95.88 \%$ with one textile layer and $134.21 \%$ with two textile layers.

The proposed FE models were accurately captured the load-carrying capacities and load-deflection relationships for both reference and strengthened columns. The analytical results show that the failure of tested specimens was due to the large transverse compressive stress concentrated in concrete at the corners of specimens. In the whole loading process stress in textile reinforcements in the corner regions is always smaller than that in other regions. However, textile fibers in corner teared earlier and leaded to the collapse of the columns. This can be explained by the reduction of tensile strength in textile reinforcements, which is related to the lateral pressure and the bending stresses of the filaments at the crack edges. Compare to the original strength in the uni-axial tensile test, the confined stress in the 
corner of the column reduced significantly the tensile failure strength of textile reinforcement. However, due to the limited number of specimens tested, further experimental investigations of the effect of corner radius for a wider range of geometric and material parameters are required to confirm these conclusions.

\section{Funding and Acknowledgement}

The research is funded by Ministry of Education and Training under the grant number CT2020.04.GHA.04. This finance is gratefully acknowledged. The authors would wish to specially thank the University of Transport and Communications for support in the study.

\section{Conflicts of Interest}

The authors declare no conflict of interest.

\section{References}

[1] Ortlepp, Regine, Andy Lorenz, and Manfred Curbach. "Column Strengthening with TRC: Influences of the Column Geometry onto the Confinement Effect.” Advances in Materials Science and Engineering 2009 (2009): 1-5. doi:10.1155/2009/493097.

[2] Triantafillou, Thanasis C., Catherine G. Papanicolaou, Panagiotis Zissimopoulos, and Thanasis Laourdekis. "Concrete confinement with textile-reinforced mortar jackets." ACI Materials Journal 103, no. 1 (2006): 28-37.

[3] Ortlepp R. "Increased efficiency of column strengthening with TRC by addition of short fibres in the fine-grained concrete matrix." Conference: High Performance Fiber Reinforced Cement Composites (HPFRCC), at Stuttgart, Vol. 7 (June 2015).

[4] Bamdad, Mahdi, Abdolreza Sarvghad Moghadam, and Mohammad Javad Mehrani. "Finite Element Analysis of Load Bearing Capacity of a Reinforced Concrete Frame Subjected to Cyclic Loading." Civil Engineering Journal 2, no. 5 (May 30, 2016): 221-225. doi:10.28991/cej-2016-00000028.

[5] De Caso y Basalo, Francisco J., Fabio Matta, and Antonio Nanni. "Fiber Reinforced Cement-Based Composite System for Concrete Confinement." Construction and Building Materials 32 (July 2012): 55-65. doi:10.1016/j.conbuildmat.2010.12.063.

[6] Trapko, Tomasz, and Michał Musiał. "Effect of PBO-FRCM Reinforcement on Stiffness of Eccentrically Compressed Reinforced Concrete Columns.” Materials 13, no. 5 (March 9, 2020): 1221. doi:10.3390/ma13051221.

[7] Colajanni, Piero, Fabrizio De Domenico, Antonino Recupero, and Nino Spinella. "Concrete Columns Confined with Fibre Reinforced Cementitious Mortars: Experimentation and Modelling." Construction and Building Materials 52 (February 2014): 375-384. doi:10.1016/j.conbuildmat.2013.11.048.

[8] Donnini, Jacopo, Simone Spagnuolo, and Valeria Corinaldesi. "A Comparison between the Use of FRP, FRCM and HPM for Concrete Confinement.” Composites Part B: Engineering 160 (March 2019): 586-594. doi:10.1016/j.compositesb.2018.12.111.

[9] Colajanni, Piero, Marinella Fossetti, and Giuseppe Macaluso. "Effects of Confinement Level, Cross-Section Shape and Corner Radius on the Cyclic Behavior of CFRCM Confined Concrete Columns." Construction and Building Materials 55 (March 2014): 379-389. doi:10.1016/j.conbuildmat.2014.01.035.

[10] ACI Committee. "ACI 549.4R-13: Guide to Design and Construction of Externally Bonded Fabric-Reinforced Cementitious Matrix (FRCM) Systems for Repair and Strengthening Concrete and Masonry Structures." American Concrete Institute (2013).

[11] Bournas, Dionysios A., Panagiota V. Lontou, Catherine G. Papanicolaou, and Thanasis C. Triantafillou. "Textile-reinforced mortar versus fiber-reinforced polymer confinement in reinforced concrete columns." ACI Structural Journal 104, no. 6 (2007): 740-748.

[12] RILEM Technical Committee 232-TDT "Recommendation of RILEM TC 232-TDT: test methods and design of textile reinforced concrete." (May 2016).

[13] Zulassung Z-31.10-182. "Gegenstand: Verfahren zur Verstärkung von Stahlbeton mit TUDALIT (Textilbewehrter Beton)." Prüfstelle: DIBt, Antragsteller: TUDAG TU Dresden Aktiengesellschaft (2015).

[14] RILEM Technical Committee 250-CSM "Recommendation of RILEM TC 250-CSM: Test method for Textile Reinforced Mortar to substrate bond characterization.” (July 2018).

[15] Ortlepp, R., Lorenz, A. and Curbach, M., Umschnürungswirkung textilbewehrter Verstärkungen im Lasteinleitungsbereich von Stützen in Abhängigkeit von der Geometrie. Beton - und Stahlbetonbau, 106: 490-500, 2011.

[16] Cervenka V., Jendele L. and Cervenka J. "ATENA computational program for nonlinear finite element analysis of reinforced concrete structures.” Program Documentation, Prague, (2004).

[17] Vassilis K. P. and Andreas J. K. "Modelling confinement in concrete columns and bridge piers through 3D nonlinear finite element analysis.” fib Symposium “Keep Concrete Attractive”, Budapest (2005). 